\title{
Experimental investigations on combustion, performance and emissions characteristics of compression ignition engine powered by B100/ethanol blend
}

\author{
Wojciech Tutak ${ }^{1, *}$, Arkadiusz Jamrozik ${ }^{1}$, and Michat Pyrc ${ }^{1}$ \\ ${ }^{1}$ Czestochowa University of Technology Sciences, Faculty of Mechanical Engineering and Computer \\ Science, 42-201 Czestochowa, Armii Krajowej 21 Av., Poland
}

\begin{abstract}
In the study are presented the results of co-combustion of biodiesel B100 with ethanol fuel as blend. The 1-cylinder direct injection compression ignition engine was used during the study. Tests were conducted at a constant angle of fuel injection and constant rotational speed equal to $1500 \mathrm{rpm}$. Results of thermal cycle parameters and emission characteristics are presented. On the basis of results stated that ethanol fuel fraction in blend causes the increase in peak heat release rate. With the increase in ethanol fuel fraction the ignition delay increased but combustion duration decreased. With the increase in ethanol fuel fraction in blend thermal efficiency increased as well. It also noticed almost constant emission of $\mathrm{THC}$, the increase in $\mathrm{NO}_{\mathrm{x}}$ emissions and decrease emissions in $\mathrm{CO}$ and $\mathrm{CO}_{2}$.
\end{abstract}

\section{Introduction}

Diesel engines are widely used to power engineering devices for its good durability and thermal efficiency. On the other hand these engines are major contributors of air pollutant emission such as carbon monoxide $(\mathrm{CO})$ and nitrogen oxides $\left(\mathrm{NO}_{\mathrm{x}}\right)$ [1]. Biofuels are a renewable, nontoxic, eco-friendly and sustainable alternative fuel for compression ignition engines. Biodiesel has obtained much attention as an alternative fuel to reduce greenhouse and combustion emissions. There has been a wide-spread study on biodiesel-fuelled engine performance and combustion emission [2,3]. Biodiesel (B100) is considered as one of the most promising alternative fuels for internal combustion engine. Biodiesel fuel is considered as friendly fuel to co-combustion with other biofuels using blends or dual fuel systems. The use of biodiesel as the alternative diesel engine fuel is increasing rapidly. However, alcohol such as ethanol is competitive alternative fuel due to their liquid nature, high oxygen content and their production from renewable biomass. Ethanol is a form of renewable energy and it can be produced from carbon based agriculture feed stocks [4]. Ethanol fuel can be considered as a renewable fuel. It has been identified that the usage of biodiesel fuel reduces carbon monoxide, hydrocarbon and particulate matter emissions but

* Corresponding author: tutak@imc.pcz.czest.pl 
nitric oxide emissions are increased compared to diesel fuel operation [5]. Because of advantages and the increasing share of biofuels in fuel market researches on their efficient use are still needed. B100 can be burned in diesel engine and it can be mixed with other fuels such as diesel or oxygenated fuels. Authors [6] investigated the diesel engines fuelled with $20 \%$ biodiesel-diesel blended fuel. The study revealed that the maximum torque achievable with the biodiesel-diesel blended fuel was slightly lower than that achievable with neat diesel fuel at high-load conditions. Smoke was decreased by more than $20 \%$ in all modes. Authors [7] investigated operate parameters of diesel engine powered by diesel fuel, rape seed methyl ester and methanol. They stated that adding methanol to biodiesel in high loads reduced $\mathrm{CO}$ in $2-13 \%$ and in whole engine load range $-13-45 \%$ reduced concentration of soot. However emission rates of $\mathrm{NO}_{x}, \mathrm{HC}$ and $\mathrm{CO}_{2}$ were close to or higher than reference diesel fuel. Nowadays renewable fuels are increasingly used in dual fuel engines $[8,9]$. Ethanol is a biomass based renewable energy source, which can be produced with relatively low cost. Ethanol for a long time was considered as curious engine fuel. At first ethanol was associated with spark-ignition engines. In recent years ethanol is used as a fuel for diesel engines [10]. It is utilized in both methods: blend or dual fuel co-combustion [8-12]. There are some work considered the use of the mixtures of mineral diesel with biodiesel and it impact on operating parameters and emission. Authors [13] stated that brake specific fuel consumption increases with higher percentage of biodiesel in the blends. Brake thermal efficiency decreases with the increased percentage of biodiesel in the blends. $\mathrm{CO}$ and $\mathrm{THC}$ emissions are improved with the addition of biodiesel to diesel. $\mathrm{NO}_{\mathrm{x}}$ emission is found to be increased with pure biodiesel compared to mineral diesel [13]. Some authors investigated the burning of mineral diesel-biodiesel-ethanol mixtures and the impact of that fuel on operating parameters and emission [14]. The experimental results showed that the performance of CI engine was improved with the use of that blend. Exhaust emissions are also improved. Tse et al. [15] presented results of the combustion characteristics and particulate emissions of a diesel engine fuelled with diesel-biodiesel-ethanol blended fuel. They stated that ethanol causes higher peak in HRR, longer ignition delay. They also stated that ethanol causes shorten the combustion duration resulting in longer premixed and shorter diffusive combustion duration when compared with biodiesel [15]. The emphasis is also on the search for sources of alternative fuels for engines and improvement of combustion systems [16-19]. Co-combustion of fuels is used not only in relation to liquid or gas fuels but it is used for solid fuels as well [1,20-22].

In recent years several experimental studies are carried out, it is evident that further studies are necessary for a better understanding on the application of ethanol-biodiesel blend in diesel engines. In this paper is investigated the various ethanol fuel (EF) fraction in blend with biodiesel (B100) on engine performance and emission. In this paper are presented results of investigation of one-cylinder direct injection air cooled diesel engine in which is made the attempt to burn a mixture of diesel-ethanol with large ethanol fuel (EF) fraction.

\section{Experimental setup}

The study used the 1-cylinder direct injection natural aspired compression ignition engine. Detailed engine specifications are presented in Table 1. Tests conducted at a constant angle of diesel fuel injection and constant rotational speed equal to $1500 \mathrm{rpm}$. The test stand equipped with measurement system and additional supply system with regulated pressure of fuel supplied mechanical fuel pump (Fig. 1).

Measuring system:

- Exhaust gas analyzer: THC, $\mathrm{CO}, \mathrm{CO}_{2}, \mathrm{O}_{2}-$ Bosch BEA 350: THC: range 0 - 9999 ppm vol, accuracy: $12 \mathrm{ppm}$ vol, $\mathrm{CO}$ : range $0-10 \%$ vol, accuracy: $0.06 \%$ vol, $\mathrm{CO}_{2}$ : range 0 - 
$18 \%$ vol, accuracy: $0.4 \%$ vol, $\mathrm{O}_{2}$ : range $0-22 \%$ vol, accuracy: $0.1 \%$ vol, $\lambda$ : range 0.5 -9.999, accuracy: 0.01,

- Exhaust gas analyzer: $\mathrm{NO}_{\mathrm{x}}$ - Radiotechnika AI9600: acuracy: 32 ppm for range 0 - 1000 ppm,

- In-cylinder pressure sensor - Kistler 6001, sensitivity: $\pm 0.5 \%$,

- Charge amplifiers - Kistler 5001, linearity of FS $< \pm 0,05 \%$,

- Air/Fuel Ratio Meter LM-2, range 7.35-22.38,

- Resolution for the data acquisition system - 1.0 CA deg,

- Data acquisition module - National Instruments USB-6251 - 16 bits resolution, sampling frequency $20 \mathrm{kHz}$.

At each mode of operation, the engine was allowed to run a few minutes until the exhaust gas temperature and exhaust gas composition have attended steady-state values and data acquisition process was subsequently conducted. The ambient temperature was maintained at a constant level. Each experiment was conducted three times and the results were found to agree with each other with the $95 \%$ significance level.

Table 1. Main engine parameters.

\begin{tabular}{|c|c|c|}
\hline Parameter & Value & unit \\
\hline Displacement volume & 0.573 & $\mathrm{dm}^{3}$ \\
\hline Bore & 90 & $\mathrm{~mm}$ \\
\hline Stroke & 90 & $\mathrm{~mm}$ \\
\hline Compression ratio & $17: 1$ & - \\
\hline Rated power (at 3000 rpm) & 7 & $\mathrm{~kW}$ \\
\hline Crankshaft rotational speed & 1500 & $\mathrm{rpm}$ \\
\hline Injection pressure & 210 & bar \\
\hline Injection timing & 17 & deg bTDC \\
\hline
\end{tabular}

Biodiesel (B100) has physical properties similar to those of conventional diesel fuel. It is also non-toxic and biodegradable. Ethanol fuel (EF) which used to diesel engine powering it was wet ethanol which consisted $89 \%$ of $\mathrm{C}_{2} \mathrm{H}_{5} \mathrm{OH}$ and $11 \%$ of $\mathrm{H}_{2} \mathrm{O}$. The blend of $\mathrm{EF}$ and diesel fuel showed separation, which hinders the formation of usable fuel blends. However, the use of biodiesel gives close to stabile and homogenous blend

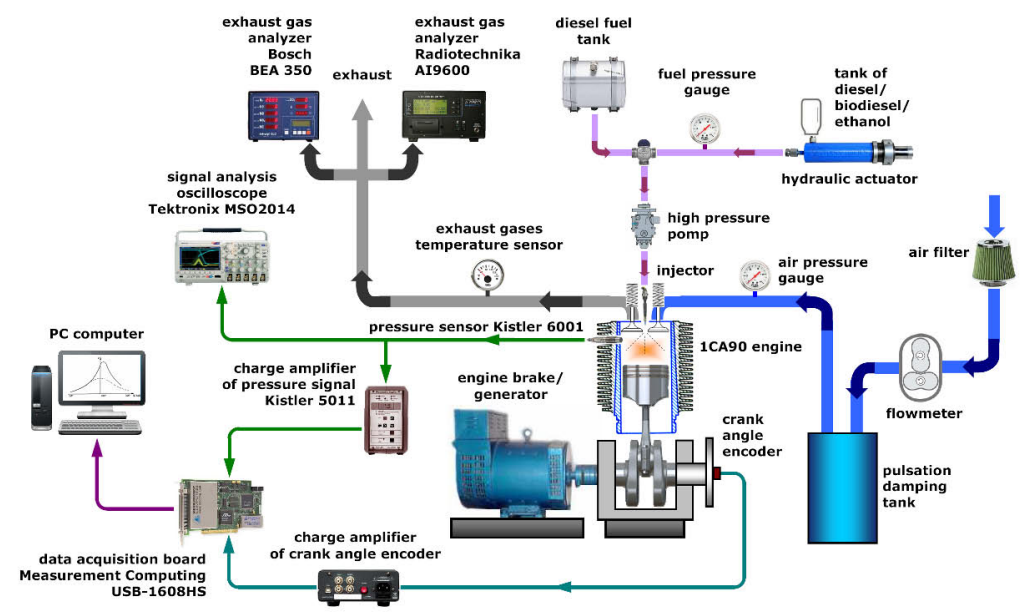

Fig. 1. Diagram of the experimental setup. 
Biodiesel molecule has a polar end with affinity for ethanol, which is also polar in nature, thus, biodiesel can be used as an alternative stabilizer in preventing the separation of ethanol from diesel fuel [15]. Ethanol fuel as a fuel for compression ignition engine generally is used by blending with conventional diesel fuel or with using dual fuel technology [8,23]. Analyzing the usefulness of alcohol to co-combustion in IC engine it should be taken into account its properties such as: lower heating value (LHV) and also stoichiometric air fuel ratio $\left(\mathrm{A} / \mathrm{F}_{\mathrm{st}}\right)$ and heat of evaporation. Some of the disadvantages of alcohol fuels are low lubricity, difficulty of vaporization and high-auto-ignition temperature. Ethanol contains oxygen atom so that it can be viewed as partially oxidized hydrocarbon [4]. The main difficulties are more ethanol fuel then diesel fuel is required by mass and volume. Additionally the poor auto-ignition capability of ethanol is responsible for severe knock due to rapid burning of vaporized alcohol and combustion quenching caused by high latent heat of vaporization.

Table 2. Fuels properties.

\begin{tabular}{|c|c|c|}
\hline Properties & $\mathrm{B} 100$ & Ethanol \\
\hline Molecular formula & $\mathrm{CH}_{3}\left(\mathrm{CH}_{2}\right)_{\mathrm{n}} \mathrm{COOH}_{3}$ & $\mathrm{C}_{2} \mathrm{H}_{5} \mathrm{OH}$ \\
\hline Cetane number & 56 & $\sim 11$ \\
\hline Lower heating value, $(\mathrm{MJ} / \mathrm{kg})$ & 37.1 & 26.9 \\
\hline Density at $20^{\circ} \mathrm{C}, \mathrm{kg} / \mathrm{m}^{3}$ & 855 & 789 \\
\hline Viscosity at $40^{\circ} \mathrm{C},(\mathrm{mPa} \mathrm{s})$ & 4.51 & 1.1 \\
\hline Heat of evaporation, $(\mathrm{kJ} / \mathrm{kg})$ & 250 & 840 \\
\hline Stoichiometric air fuel ratio & 12.5 & 9.0 \\
\hline Flash point, $\left({ }^{\circ} \mathrm{C}\right)$ & $>101$ & 425 \\
\hline Oxygen content, wt $\%$ & 10.8 & 34.8 \\
\hline Carbon content, wt $\%$ & 77.1 & 52.2 \\
\hline Hydrogen content, wt $\%$ & 12.1 & 13 \\
\hline
\end{tabular}

In Fig. 2a are presented the heat of evaporation and LHV of B100 and EF. Additionally, LHV of alcohol is lower in comparison to biodiesel fuel hence to obtain the same engine performance the higher amounts of alcohol should be provided (Fig. 2).
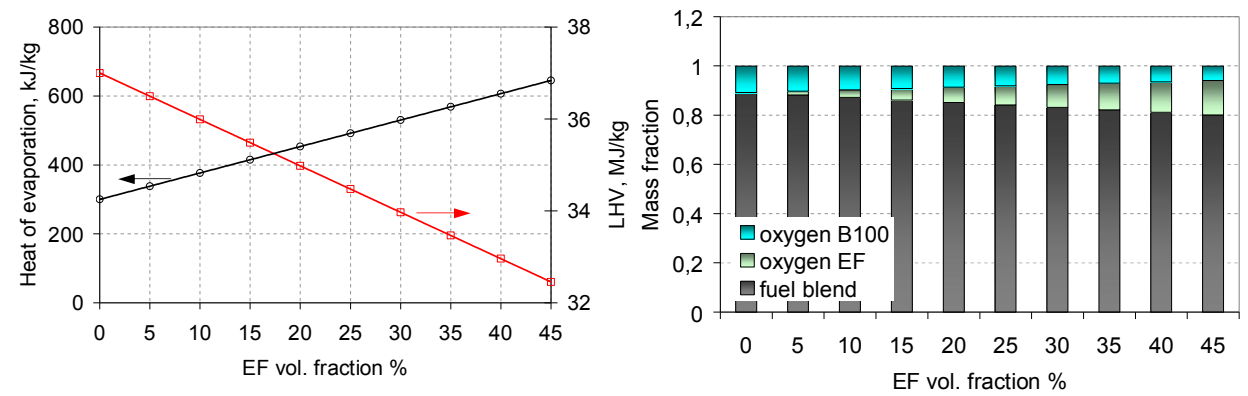

Fig. 2. Heat of evaporation and lower heating value (a) and oxygen mass fraction (b) in blend.

Biodiesel is characterized by lover value of LHV than conventional diesel fuel of near to $12 \%$ because of presence of substantial amount of oxygen in the fuel, but B100 has higher value of cetane number than diesel fuel. Biodiesel in comparison to diesel fuel has higher 
cetane number which could enhance the cetane number of biodiesel-ethanol blend. Whereas the diesel engine prefers fuels of high cetane number which makes auto-ignition process easily and gives small ignition delay. During the tests used BE blends in large values of ethanol fuel fraction up to $45 \%$. As the limit of EF fraction in blend was quality of the engine work and possibility to auto-ignition of used fuels blend. As presented in Fig. 2a with the increase in EF fraction the value of heat of evaporation increased as well. It caused difficulty in vaporization of fuel dose and connected with decreased of cetane number by EF participation it worsens auto-ignition process. In case of B100 fuel the oxygen mass fraction is equal to $10.8 \%$. In EF the oxygen mass fraction is $34.8 \%$. As presented in Fig. $2 \mathrm{~b}$ with the increase in EF fraction the oxygen fraction in blend increases as well.

\subsection{Test method}

Analysis of combustion process in the internal combustion engine usually is carried out with the rate of heat release. Heat release rate (HRR) is calculated on the basis of the measured in-cylinder pressure data and crank angle readings. The basis for determining the heat release rate is the first law of thermodynamics and the equation of state [23]. A parameter indicating the performance of the engine is the indicated mean effective pressure which is determined on the basis of the instantaneous pressure in the cylinder. On the basis of pressure courses determined the factor of unrepeatability as $C O V_{I M E P}$ [23]. The averaged value of IMEP of the three measurements containing 100 recorded engine cycles [bar]. After rearranging and simplifications, the heat release rate vs. crank angle is obtained in well-known form as follows:

$$
H R R=\frac{1}{\kappa-1}\left[\kappa p \frac{d V}{d \varphi}+V \frac{d p}{d \varphi}\right]
$$

where: $\kappa$ - isentropic exponent, $V$-cylinder volume, $p$ - in cylinder pressure.

Instantaneous cylinder volume $V$ is precisely described by engine geometry. Due to omitting as follows: heat transfer to walls, crevice volume, blow-by and the fuel injection effect, the resulted heat release rate is termed as the net heat release rate. The cumulative net heat released is obtained by integrating Eq. 1 over the crank angle $\varphi$.

A parameter indicating the performance of the engine is the indicated mean effective pressure which is determined on the basis of the instantaneous pressure in the cylinder. Indicated pressure is calculated as:

$$
I M E P=\frac{1}{V_{d}} \int_{0}^{720} p \frac{d V}{d \varphi}
$$

where: $V_{d}$ - displacement volume $\left[\mathrm{m}^{3}\right]$,

The indicated thermal efficiency (ITE) is calculated on the basis of equation:

$$
I T E=\frac{I M E P \cdot V_{d} \cdot 0.5 \cdot n \cdot t}{V_{f} \cdot \rho_{f} \cdot L H V}
$$

where: $I M E P$ - indicated mean effective pressure [\%], $V_{f}$ - volume of fuel delivered to the engine cylinder $[\mathrm{m} 3], \rho_{f}$ - fuel density $\left[\mathrm{kg} / \mathrm{m}^{3}\right], L H V$ - lower heating value of fuel $[\mathrm{MJ} / \mathrm{kg}]$, $n$ - rotational speed of engine, $t$ - time consumption of the fuel delivered to the engine cylinder [min].

On the basis of pressure courses determined the factor of unrepeatability as $C O V_{I M E P}$.

$$
C O V_{I M E P}=\frac{\sigma_{I M E P}}{I M E P_{\text {mean }}} \cdot 100 \%
$$

where: $\sigma_{I M E P}-$ standard deviation of IMEP. 
The standard deviation of the IMEP:

$$
\sigma_{I M E P}=\sqrt{\frac{1}{N-1} \sum\left(I M E P_{i}-I M E P_{\text {mean }}\right)^{2}}
$$

where: $I M E P_{i}$ - value of $I M E P$ in following cycles [bar], IMEP mean - averaged value of $I M E P$ of the three measurements containing 100 recorded engine cycles [bar].

\section{Results}

The researches conducted with various fuel blends of B100/EF. It was using blends with volumetric fractions of EF from 5 to $45 \%$ (blend with 5\% of EF - BE05). During experimental research recorded 100 consecutive engine operation cycles with resolution of $1 \mathrm{deg}$ of CA. The results are used to evaluate the combustion process. The heat release rate are calculated on the basis of the measured in-cylinder pressure data and crank angle readings individually for each cycle and than these were averaged. On the basis of measurement data the operating parameters as IMEP and ITE of engine were determined. The study was conducted at a constant angle of the start of fuel injection equal to $17 \mathrm{deg}$ before TDC. This constant injection timing of the test engine was due to the fact that such engine is still manufactured in Poland and it is used to power various devices.

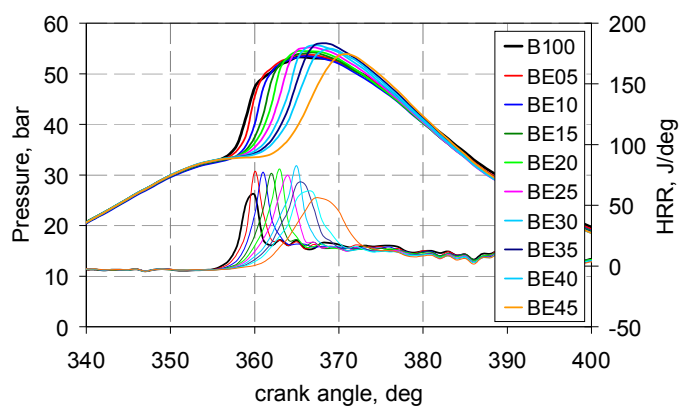

Fig. 3. Pressure and heat release rate traces of test engine.

The variation of in-cylinder pressure and heat release rate are shown in Fig. 3 for different ethanol volumetric fraction from 5 to 45 , respectively. As a reference values were taken results of B100 burning in the test engine. Each pressure waveform is obtained by averaging 100 cycles of engine operation. The peak in-cylinder pressure occurs further away from the TDC (top dead center) in the expansion stroke with increase of EF fraction, which is similar to the results of Qi et al. [24].

Observing the pressure waveform can be seen that with increasing share of EF in blend the combustion process take place with higher ignition delay. In case of engine powered by biodiesel the peak pressure $\left(\mathrm{p}_{\max }\right)$ was equal 53 bar and was achieved at 6 deg after TDC. With the increase of EF fraction in blend $p_{\max }$ reach highest values and reached for higher values of crank angles after TDC. In Fig. 3 are presented the HRR traces of co-combustion of $\mathrm{B} 100$ and $\mathrm{EF}$ as well. On the basis of these data combustion process can be characterized. It can be stated that EF fraction in blend causes the increase in peak HRR. Up to BE30 blend noticed the increase in max value of HRR. The increase in peak HRR was about $30 \%$ in comparison with B100. The peak heat release rate increases and up to BE30 is kept near on the same level. After exceeding 30\% of EF fraction in blend the HRR started to decrease due to lover value of LHV of blend and relatively high value of heat of evaporation. It was du to high fraction of EF in blend which already causes significant increase in the amount of heat needed to evaporate the fuel dose. Increased peak values of HRR are directly related to thermal load. On the basis of HRR traces by integration the 
MFB traces are determined. The MFB traces are used to the combustion phases determined. The ignition delay (ID) is defined as the angle from the beginning of fuel injection to $10 \%$ of MFB and combustion duration (CD) as a range of crank angle 10-90\% of MFB. Ignition delay period consist of physical delay and chemical delay which occur simultaneously. In the physical delay takes place atomization, vaporization and mixing of air fuel, and in the chemical delay attributed pre-combustion reactions [25].
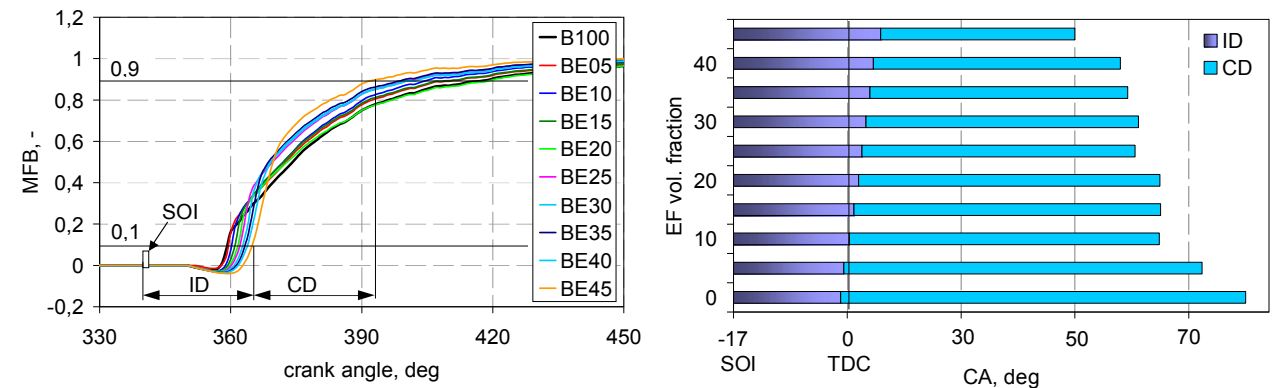

Fig. 4. Mass fraction burned (a) and combustion phases (b).

In Fig. 4a are presented courses of mass fraction burned (MFB) for combustion of all analyzed blends. There are indicated the periods of ignition delay (ID) and combustion duration (CD). In Fig. $4 \mathrm{~b}$ are presented the combustion phases of test engine. Because ethanol has a lower cetane number and higher heat of vaporization requirements than diesel, ethanol blended fuels also decrease overall cetane number and increase ignition delay $[26,27]$. It can be stated that with the increase in EF fraction the ignition delay increased. Ethanol blended fuels exhibited unstable ignition characteristics. The increase in ignition delay at BE45 blend in comparison with B100 was equal to 6 deg CA. The inverse relationship was obtained in case of combustion duration. With the increase in EF fraction in blend the combustion duration decreased. In case of BE45 the combustion duration was 2-times lower in comparison with B100 fuel. For the pure biodiesel fuelling the ratio of CD to ID was 3.75 but in case of $45 \%$ of EF fraction this ratio was 1.32 . Similar results are obtained by Tse et al. [15].
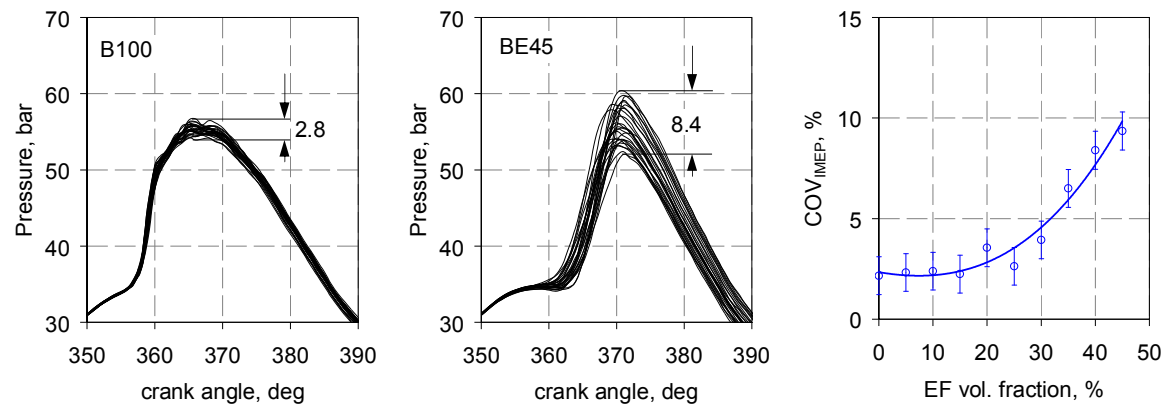

Fig. 5. Cycles variations of the engine powered by B100 and BE45 and unrepeatability of IMEP.

It was due to two characteristic properties of EF. The first it is heat of evaporation which cause the ignition delay increase by lowering the combustion temperature. The second it is oxygen content that is obviously favors the combustion process. Both of these properties counteract each other during the combustion process. Donahue et al. stated that higher oxygen content in the spray (from oxygenated fuel) reduced pyrolysis and increased oxidation, thus shortening the combustion duration [28]. As seen in the Fig. 4 all the blends give faster combustion in all analyzed cases than biodiesel which could compensate the ignition delay in start of combustion. 
The faster combustion process could lead to the increase in ITE which is visible in the Fig. 6. In Fig. 5a are presented the peak in-cylinder pressure variations for the test engine powered by B100 and blend BE45. In case of powering by pure biodiesel the peak pressure variation are equal to 2.8 bar but in case of BE45 it is 8.4 bar. The unrepeatability of successive cycles of engine operation has the impact not only on engine performance but also on the emission of toxic components of exhaust gases. With the increase in EF fraction in blend it observed the increase in unrepeatability of cycles (Fig. 5). Despite the significant unrepeatability of consecutive engine cycles ware there no cycles without combustion. In all analyzed cases the $C O V_{I M E P}$ was lower then $10 \%$. The increase value of $C O V_{I M E P}$ is directly connected with the unstable auto-ignition characteristic of ethanol-biodiesel bend. With the increase in EF fraction the cetane number decreased at the same time, which worsens the process of auto-ignition as well.
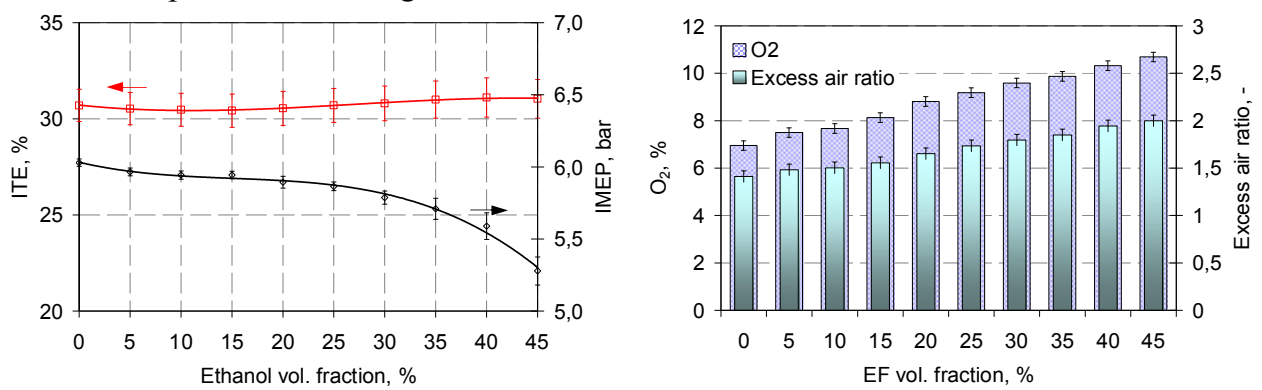

Fig. 6. Indicated thermal efficiency (ITE) and indicated mean effective pressure (IMEP) and the oxygen content in the exhaust gases.

In Fig. 6a is presented the indicated thermal effciiency and the indicated mean effective pressure for burned blends. The injection system ensures a constant volume dose of fuel that with the increase in EF fraction the energy value of the fuel dose decreased. Of course, it would then affect the value of IMEP. However, the decrease in the value of IMEP was only 0.56 bar at BE45. The more visible decrease in IMEP noticed after exciding $30 \%$ of $\mathrm{EF}$ in blend. On of the most important characteristics of thermal cycle of internal combustion engine is thermal efficiency. In analyzed cases with the EF fraction increase ITE increased as well. Similar results obtained by Zhu et al. [28]. Up to BE25 blend ITE was kept near on the same level. The measurement error of IMEP is $\delta I M E P=2.1 \%$ and error of ITE is $\delta I T E=3.2 \%$. In Fig. $6 \mathrm{~b}$ is presented the oxygen content in the exhaust of engine powered by various blends. With the increase in EF fraction in blend while decreasing amount of hydrocarbon in the blends causes lower requirement of oxygen to combustion process. The increasing in EF fraction causes the increasing of stoichiometric air fuel ratio of the blend.

The $\mathrm{NO}_{\mathrm{x}}$ emission increased with the EF fraction in blend (Fig. 7). The highest value of $\mathrm{NO}_{\mathrm{x}}$ emission noticed for $45 \%$ of EF fraction equal to $4.4 \mathrm{~g} / \mathrm{kWh}$ and it was higher by $30 \%$ in comparison with B100 fuelling. In case of EF fractions combustion process occurred faster with higher in-cylinder pressure and temperature as well. The $\mathrm{NO}_{\mathrm{x}}$ formation rate strongly depends on temperature and oxygen presence. In compression ignition engine generally the excess air ratio is higher then one and additionally locally the oxygen is supplied by the fuel (Fig. 3). In the combustion chamber of the engine during relatively short premixed combustion phase are conditions to $\mathrm{NO}_{\mathrm{x}}$ formation.

The presence of intrinsic oxygen can also cause of the slightly increased $\mathrm{NO}_{\mathrm{x}}$ emission for the blends. Higher in-cylinder pressure could contribute to the increased NOx emissions, due to the increased peak combustion temperature at high engine loads [29]. 

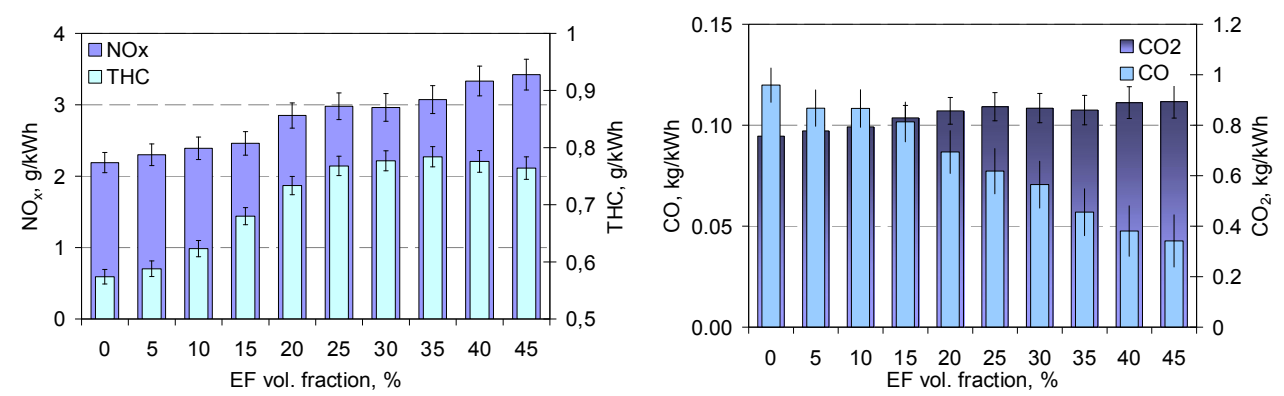

Fig. 7. Emission of $\mathrm{THC}, \mathrm{NO}_{\mathrm{x}}$ and $\mathrm{CO}, \mathrm{CO}_{2}$.

Analyzing the emissions of THC it can be stated that it was noticed slightly the increase in THC emission during the tests. The highest THC emission was indicated for $35 \%$ of EF fraction in blend and it was higher of about $30 \%$ compared to pure B100 powering. In the literature it has also been observed that the presence of alcohol in the blends contributes the increase in THC emission [25]. The THC emission is higher since temperature is lower due to the higher heat of evaporation of ethanol fuel thus combustion poor. Variations of $\mathrm{CO}$ and $\mathrm{CO}_{2}$ emissions as a function of blend fractions are presented in Fig. 7. Emissions of CO depend on the air-fuel ratio relative to the stoichiometric proportion. Reach combustion process invariably produces $\mathrm{CO}$ and emissions increase nearly linearly with the deviation of the stoichiometric [4]. For all analyzed blends the specific emission of $\mathrm{CO}$ was decreased. It can be stated that combustion process occurred more complete with EF fraction. As compared to baseline biodiesel, ethanol blended fuels result in lower $\mathrm{CO}$ emissions in this case. Higher specific emission of $\mathrm{CO}_{2}$ is due to lower values of IMEP.

\section{Conclusions}

The paper presents results of co-combustion of biodiesel B100 with ethanol fuel as a blend. In the researches used the mixture of up to $45 \%$ by volume of ethanol fuel. The analysis of the operating parameters and emission of the engine are presented in the study. The following main results are summarized:

- up to BE35 obtained the increase in peak pressure, with the increase in EF fraction in blend observed the increase in unrepeatability of cycles, up to BE30 blend noticed the increase in peak of HRR. The increase was about $30 \%$ in comparison with B100, the increase in ignition delay at BE45 blend in comparison with $\mathrm{B} 100$ was equal to $6 \mathrm{deg}$ $\mathrm{CA}$, with the increase in $\mathrm{EF}$ fraction in blend the combustion duration decreased. In case of BE45 the combustion duration was 2-times lower in comparison with B100 fuel, with the increase of EF the lower IMEP obtained but ITE was at the same level as in case of B100. The NOx emission increased with the EF fraction in blend up to BE35.

- emissions of THC increased with the increase in EF fraction,

- lower emission of $\mathrm{CO}$ noticed which indicates that combustion process occurred more complete in EF presence.

Summing up the results of research can be concluded that blend of B100 with ethanol fuel can be burned in the compression ignition engine with acceptable operating parameters and emission. Fuel B100 relatively well mixed with ethanol and form a relatively stable mixture. 


\section{References}

1. G. Szendr, A. Török, Transport 29, 5 (2014)

2. A. Ghurri, K. Jae-duk, S. Kyu-Keun, J. Jae-Youn, K. Hyung Gon, Journal of Mechanical Science and Technology 25, 4 (2011)

3. M. Mikulski, K. Duda, S. Wierzbicki, Fuel 164, 13 (2016)

4. B.S. Chauhan, N. Kumar, S.S. Pal, Y.D. Jun, Energy 36, 8 (2011)

5. K. Anand, R. P. Sharma, P. S. Mehta, Biomass and bioenergy 35, 8 (2011) 533-541.

6. S. Park, H. Kim, B. Choi, Journal of Mechanical Science and Technology 23, 9 (2009)

7. J. Zaglinskis, K. Lukács, Á. Bereczky, Fuel 170, 15 (2016)

8. W. Tutak, Energy Conversion and Management 86, 8 (2014)

9. W. Tutak, K. Lukács, S. Szwaja, A. Bereczky, Fuel 154, 10 (2015)

10. A. Murcak, C. Hasimoglu, I. Çevik, H. Kahraman, Fuel 153, 8 (2015)

11. A. Jamrozik, W. Tutak, Bulletin of the Polish Academy of Sciences Technical Sciences 62, 11 (2014)

12. Z. Şahina, O. N. Aksub, Renewable Energy 77, 11 (2015)

13. A. Datta, S. Palit, B.K. Mandal, Journal of Mechanical Science and Technology 28, 5 (2014)

14. H. Aydin, C. Ilkılıç, Applied Thermal Engineering 30, 5 (2010)

15. H. Tse, C. W. Leung, C.S. Cheung, Energy 83, 7 (2015)

16. A. Jamrozik, Journal of Mechanical Science and Technology 29, 9 (2015)

17. W. Tutak, A. Jamrozik, Thermal Science 18, 10 (2014)

18. M. Kisielewska, M. Dębowski, M. Zieliński, Bioprocess and Biosystems Engineering 38, 10 (2015)

19. A. Jamrozik A., W. Tutak, Chemical and Process Engineering 32, 4 (2011)

20. A. Kijo-Kleczkowska, K. Sroda, M. Kosowska-Golachowska, T. Musiał, K. Wolski, Fuel 170, 19 (2016)

21. A. Kijo-Kleczkowska, K. Środa, M, Kosowska-Golachowska, T. Musiał, K. Wolski, Waste Manage 53, 16 (2016)

22. M. Kosowska-Golachowska, A. Kijo-Kleczkowska, A. Luckos, K. Wolski, T. Musiał, Archives of Thermodynamics 37, 1 (2016)

23. W. Tutak, A. Jamrozik, M. Pyrc, M. Sobiepański, Fuel Processing Technology 149, 9 (2016)

24. D.H. Qi, H. Chen, R.D. Matthews, Y.ZH. Bian, Fuel 89, 6 (2010)

25. H. Zou, L. Wang, S. Liu, Y. Li. Front. Energy Power Eng. China 2, 3 (2008)

26. N. Yilmaz, F. M. Vigil, A. B. Donaldson, T. Darabseh, Fuel 115, 3 (2014)

27. S. Lennox, K. Lukács, A. Torok, A. Bereczky, M. Mbarawa, A. Penninger, A. Kolesnikov, Fuel 107, 9 (2013)

28. L. Zhu, C.S. Cheung, W.G. Zhang, Z. Huang, Fuel 90, 7 (2011)

29. F. Lujaji, K. Lukacs, A. Bereczky, M. Mbarawa, Fuel 90, 5 (2011) 